\title{
ÁNGEL RAMA Y LA CONSTRUCCIÓN \\ DE UNA LITERATURA LATINOAMERICANA
}

\author{
POR \\ SUSANA ZANETTI \\ Universidad de Buenos Aires
}

Si nos avenimos al testimonio de la memoria - aun si lo entendemos configurado por la coherencia retrospectiva propia de lo autobiográfico-se nos impone una imagen de Ángel Rama, muy sostenida en el tiempo, de su relación con la literatura, caracterizada por el gesto totalizante que implica siempre, en sus múltiples facetas, una doble vertiente. Sus breves notas de 1978 compaginan un lector voraz y a la vez tempranamente inclinado a la sistematización, en el recinto típico del investigador: la Biblioteca Nacional. ${ }^{1}$

El sesgo insinuado en estos primeros pasos se va definiendo a comienzos de la década del sesenta, tanto en sus preocupaciones comoen sus manifestaciones. ${ }^{2}$ $\mathrm{Su}$ inserción en el campo intelectual uruguayo se nos presenta encarando problemas y funciones que ya no abandona, por el contrario, las profundiza y las expande combinando siempre la incitación de lo inmediato con la reflexión sistematizada. Las lecturas y otras experiencias de su actividad posterior contribuyen a la puesta en escena de ciertas cuestiones básicas - corregidas, revisadas, ampliadas-planteadas en los primeros años de su incorporación a esa franja intelectual de la izquierda independiente que nuclea Marcha. Reacio al encandilamiento de las teorias literarias de moday sin enrolarse francamente

\footnotetext{
1 "Desde mi infancia, leer ha sido para mí una especie de felicidad privada para la que apenas han existido algunos sustitutos. Tenía yo doce años cuando acudía a la Biblioteca Nacional a leer, y lo curioso es que las lecturas eran como jornadas de trabajo. Durante horas leía lo que entonces, en mi adolescencia, eran los autores preferidos, la literatura española. Llevaba una especie de cuadernito en el que anotaba lo que leía: el nombre del autor, el tema del libro y el comentario personal”. En “Angel Rama y su felicidad íntima: leer" (El Universal, Caracas, 9 de julio de 1978). Citado en Carina Blixen y Alvaro BarrosLémez; Cronología y bibliografía de Angel Rama (Montevideo: Fundación Angel Rama 1986), 11.

${ }^{2}$ A principios de los sesenta interrumpe su obra de creación. Hasta entonces ha estrenado tres obras de teatro - Lucrecia, 1957; La inundacion, 1958; y Queridos amigos, 1961-y ha publicado dos novelas —iOh sombra puritana!, 1951; y Tierra sin mapa, 1961. No editó sus cuentos premiados en 1958, incluidos en Desde esta orilla.
} 
en ninguna de ellas, atento cada vez más a las posibilidadesinterpretativas que abren a sus indagaciones otras disciplinas, especialmente la antropología, se mantendrá fiel a un trabajo crítico empeñado en una perspectiva totalizadora capaz de articular sistemáticamente las diversas experiencias literarias latinoamericanas en función de los vínculos que ellas guardan con los múltiples estratos sociales configuradores de las culturas continentales; un trabajo crítico que aquí aún encierra el desafío de "construir" una literatura:

Ocurre que si el critico no construye las obras, si construye la literatura, entendida como un corpus orgánico en que se expresa una cultura, una nación, el pueblo de un continente, pues la misma América Latina sigue siendo un proyecto intelectual vanguardista que espera su realización concreta. ${ }^{3}$

Si revisamos las transformaciones que Angel Rama opera con los materiales teóricos y la libertad con que los compagina para su trabajo crítico - en ese constante diálogo que nutre las respuestas a sus interrogantes: el aporte extranjero y el propio de América Latina-creo que le cabe la denominación de transculturador; que se lo puede incluir, para la producción crítica, en ese eje productivo que elaboró y sustentó en su análisis de José María Arguedas, Rulfo o García Márquez, aunque es un parámetro que empieza a emerger en textos anteriores a los incluidos en Transculturación narrativa en América Latina ${ }^{4}$ y que impregna también sus últimos trabajos, La ciudad letrada, por ejemplo, en el que traza los lineamientos particulares de esa esfera propia, la de los intelectuales.

\section{EL SISTEMA DE LAS MUÑECAS CHINAS}

En poco más de una década Angel Rama ha diagramado sus estrategias de intervención en el campointelectual uruguayo y las modalidades de su actividad escrituraria, peculiarizadas por una actitud militante que no resigna ningún espacio propicio a la tarea elegida. Será una tarea marcada por un proyecto fuertemente religador y sistematizador de las literaturas latinoamericanas: emprende la reseña o el artículo periodístico y la investigación; se propone como formador del gusto de un nuevo público masivo al mismo tiempo en que incide en los ámbitos académicos para conformar nuevas posibilidades críticas; apela a la conferencia, a la clase, al programa radial o a la polémica; actúa en las instituciones culturales del Estado y controla críticamente los modos en que ellas operan; se plantea la revisión del pasado y funda editoriales para generar espacios de circulación a los nuevos textos del presente.

s Ángel Rama, La novela en América Latina. Panoramas 1920-1980(Bogotá: Procultura, 1982).

"Transculturación narrativa en América Latina (México: Siglo XXI, 1982) incluye artículos publicados a partir de 1974. 
Es difícil resumir esta labor múltiple, casi sin tregua. Apuntaremos sólo sus lineamientos..$^{5}$ La inclinación por el teatro, que lo convierte en actor a los dieciséis años, se ramifica luego hacia la investigación - su proyecto de estudio sobre el "Origen y desarrollo del teatro nacional" de 1953- hacia la crítica periodística -en Acción, entre 1957 y 1964- y hacia la docencia -como profesor de Historia del Teatro en 1961. En adelante será docente en la Universidad Nacional y en las extranjeras, sea como profesor regular o a través del dictado de innumerables cursos en Argentina, Chile, Venezuela, Puerto Rico, Alemania o los Estados Unidos. La investigación se irá concretando en un nutrido número de artículos y libros sobre literatura uruguaya olatinoamericana, cada vez más abarcadores, cuya culminación podríamos colocar en el proyecto de una historia literaria latinoamericana planeada por el grupo de especialistas patrocinado por la Universidad de Campinas, la Universidad Simón Bolívar y la Asociación Internacional de Literatura Comparada (ALLC), con el apoyo de UNESCO. ${ }^{6}$

Su empleo en la Biblioteca Nacional de Montevideo (1949-1965) aporta experiencias significativas para sus reflexiones acerca de lainstitucionalización del saber y la conformación de un canon literario nacional. Pero más allá del peso que esta actividad cobra en sus textos, nos interesa destacar su labor cuando se hace cargo de la edición de los Clásicos Uruguayos de la Biblioteca Artigas - entre 1951 y 1958-, labor que podemos considerar como pre-anuncio de la que cumplirá con la Biblioteca Ayacucho, fundada en 1974 por la presidencia de Venezuela. La acción en este campo muestra un lado de la vertiente, complemento de la mencionada en el párrafo anterior, animada por el proyecto de diseñar no sólo una tradición literaria nacional sino también de intervenir en esa tarea "vanguardista" de construir una literatura latinoamericana, atendiendo además a su convicción de la necesidad de impulsar una lectura y una articulación del pasado que integre la herencia crítica e historiográfica con que ese pasado ya cuenta:

Confieso que ése fue uno de los motivos por los cuales fundé la Biblioteca Ayacucho: el espectáculo de un continente intelectual reclamando su identidad y su originalidad, sin citar las espléndidas obras que en siglos se habían acumulado en esta misma tierra americana, pacientemente rearticuladas por el pensamiento crítico de nuestros antecesores. ${ }^{7}$

Este esfuerzo por la legimitación de un canon, en un alto nivel institucional, encuentra su reverso en la promoción de nuevos textos y en la puesta en

\footnotetext{
${ }^{5}$ Para mayores datos consúltese la Cronología y bibliografía de Ángel Rama citada en nota 1.

'Ana Pizarro, coord., La literatura latinoamericana como proceso (Buenos Aires: Centro Editor de América Latina, 1985).

${ }^{7}$ Ángel Rama, La novela en América Latina, 16.
} 
circulación de otros poco conocidos ${ }^{8}$ o todavía inéditos, de difícil acceso para el público rioplatense, que cumple con las empresas editoras en cuya fundación o dirección interviene desde 1950, y entre las cuales se destaca sobre todo Arca. ${ }^{9}$ Actuar directamente en el mercado introduciendo nuevos valores y vitalizando perspectivas cristalizadas del pasado literario y cultural ${ }^{10}$ se corresponde con la producción crítica de Rama; ella va mostrando una atención creciente tanto hacia los momentos iniciales de la literatura-Balbuena, Eslava-como de los muy últimos - un buen ejemplo lo constituye su antología y el extenso prólogo a los "novísimos"." Ambos movimientos comparten ese ademán totalizador ya señalado, que parece no temer los riesgos de naufragio y que Rama lleva adelante como continuo work in progress, tanto por el modo de producción de sus obras - los "libros-ferrocarril" resultantes de la reunión de artículos anteriores revisados y reescritos-como por la forma en que va construyendo esa totalidad. Si podemos comprender esta actividad que no deja casi resquicio a su ingerencia en los diversos centros latinoamericanos en donde actúa como sujeta a lo que denominaba el "sistema de muñecas chinas", ${ }^{12}$ propio de las condiciones del medio intelectual de nuestros países, podemos anotar también que de tal experiencia resultan, en buena medida, las cuestiones que privilegia para ordenar esa historia problemática que replantea de la literaturalatinoamericana: los sucesivos impactos que la modernidad acarrea en nuestras sociedades y en nuestra cultura, y sus consecuencias en el letrado. Las vicisitudes ante el mercado y ante el poder, los modos posibles de acción del intelectual militante y del escritor en los marcos de sociedades dependientes y marginales orientan sus preguntas. Dice, por ejemplo, cuando revisa la renovación literaria de Venezuela a partir de la caída de Pérez Jiménez en 1958, al referirse al movimiento de Sardio:

Proclamarse afiliados a un “humanismo político de izquierda” no disimula la concepción elitista que les será reprochada ... y se evidencia en esa proclividad de los intelectuales a esperarlo todo de la pura y exclusiva enunciación de las ideas en un reiterado obsesivo afán de conducción ilustrada. Tantas veces en

\footnotetext{
${ }^{8}$ Entre ellos se destaca la edición de las obras completas de Felisberto Hernández, por las posibilidades que abrió a su difusión en Uruguay y en el resto de América.

${ }^{\circledR}$ En 1950 funda con Carlos Maggi las Ediciones Fábula. En 1960, cuando se hace cargo de la colección Letras de Hoy, de Alfa, asume también la codirección de Asir, hasta 1962, año en que funda con José Pedro Díaz la editorial Arca. Más tarde, en 1966, es cofundador de Galerna de Buenos Aires y su asesor literario durante dos años.

${ }^{10}$ En este sentido es significativa también la Enciclopedia uruguaya, de aparición semanal en fascículos (1968-1970). Rama es el responsable del plan y de la dirección general.

${ }^{11}$ Novtsimos narradores hispanoamericanos en marcha (México: Marcha Editores, 1981).

12 "Por esa época (1969) el sistema de muñecas chinas, una dentro de otras, que es la forma de trabajo de los intelectuales en los países subdesarrollados, había llegado a su delirio," afirma en Cuadernos de Marcha 19. Citado en Carina Blixen, 38.
} 


\section{ÁNGEL RAMA Y LA CONSTRUCCIÓN DE UNA LITERATURA ... 923}

tierras latinoamericanas, desde su primera aparición en el "Salón Literario" romántico de 1937 en Buenos Aires, hemos visto repetir esta esperanza, que no nos sorprende su previsible fracaso. ${ }^{13}$

Desaparecida ya esa figura del intelectual adánico y prometeico ${ }^{14}-$ preceptible aún en Marti, y por esto quizás también su insoslayable presencia y persistencia en el pensamiento de Rama-, las tensiones entre el reducto de las ideas como propio de las demandas de la acción impregnan los dilemas que acosan a los intelectuales de los sesenta. Son los replanteos de este rol respecto de la acción política directa en una situación percibida como revolucionaria, que en el ensayo sobre Salvador Garmendia interpreta transferida a una estética:

El movimiento - se refiere alEl Techo de la Ballena-funcion6 como equivalente literario y artístico de la violencia armada venezolana de la época betancourista y aun podría agregarse que sus acciones imitaron las tácticas de una lucha guerrillera, con sus bruscas acometidas, su repentismo, el manejo de una exacerbada y combativa imaginacion. ${ }^{15}$

Los engranajes del poder o las leyes propias del mercado no entrañan sometimiento, en ellos se abren brechas donde escritores e intelectuales juegan su libertad ${ }^{16}$ y sus responsabilidades como tales, conscientes de su manejo de los lenguajes simbólicos de la cultura - "No sólo sirven a un poder, sino que también son dueños de un poder ${ }^{117}$ - y una capacidad crítica militante. Sus preocupaciones sobre las transformaciones del papel del intelectual y el escritor en las sociedades latinoamericanas aparecen teñidas por su propia aventura personal y las disyuntivas que acosaron tanto a Rama como a sus contemporáneos en las décadas de los sesenta y los setenta; en este sentido podemos leer su refutación en La ciudad letrada, de ciertas posiciones al respecto:

Con demasiada frecuencia, en los análisis marxistas, se ha visto a los intelectuales como meros ejecutantes de los mandatos de las Instituciones (cuando no de las clases) que los emplean, perdiendo de vista su peculiar función de productores, en tanto conciencias que elaboran mensajes y, sobre todo, su especificidad como diseñadores de modelos culturales, destinados a la conformación de ideologias públicas. ${ }^{18}$

${ }^{13}$ Salvador Garmendia y la narrativa informalista (Caracas: Universidad Central de Venezuela, 1975), 11.

${ }^{14}$ Tulio Halperin Donghi, El espejo de la historia (Buenos Aires: Sudamericana, 1987).

${ }^{15}$ Halperín, 33.

16 Véase al respecto sus reflexiones sobre "La censura como conciencia artística" en Eco 215, setiembre de 1979.

${ }^{17}$ La ciudad letrada (Montevideo: Fundación Angel Rama, 1984), 39.

${ }^{18}$ La ciudad letrada, 38. 
La sistematización de las redes que van organizando respuestas a la modernidad - sus contactos, confluencias y transformaciones-en el espacio y en el tiempo, y la búsqueda de modos de aprehender la compenetración particular entre los diferentes estratos sociales (y sus genuinas experiencias culturales) y las élites urbanas, receptoras privilegiadas de los cambios estéticos e ideológicos de los centros europeos o norteamericanos, ${ }^{19}$ constituye un eje estructurador permanente en el trabajo crítico de Rama. El fraseo de sus temas sustantivos orienta su análisis de la gauchesca, de los fenómenos de transculturación, de la ciudad letrada, así como las tensiones entre cosmopolitismo y regionalismo no sólo vertebran estos items apuntados, sino también a esas figuras claves de la moderni dad a las que constantemente vuelve desde diferentes ángulos, como son José Martí y Rubén Darío. Como el mismo Rama reconoce, la crítica está siempre situada y datada:

Escribimos en Nuestra América sobre el papel del tiempo, sobre el tiempo perecedero, escribimos sobre la urgencia del lector y el medio y la hora que vivimos o nos vive, y sin duda el tiempo nos escribe y nos dispersa y en cenizas nos convierte. ${ }^{20}$

Así, ciertas condiciones claves para Rama del medio cultural en que debió desarrollar su actividad -los cambios cualitativos producidos por la irrupción de los medios de comunicación masiva, la penetración cultural y la incidencia de las multinacionales - junto a los conceptos de colonización y dependencia, son coordenadas básicas para debatir - y debatirse en- la figura de Dario. En Rubén Darío y el modernismo señala cómo Darío, en momentos de cambios intensos en las sociedades latinoamericanas, elige con acierto instalarse en la modernidad y operar la transformación de la lengua poética del español mediante "la apropiación del instrumental europeo contemporáneo", analizando fundamentalmente el papel que cumplió su trabajo en ese nuevo mercado que se conformaba hacia fines de siglo, especialmente en el periodismo. Discute y rechaza el juicio de Pedro Salinas acerca del carácter negativo que tuvo la actividad periodística en el Darío poeta, "desde su peculiar actitud de clero", a partir de una perspectiva que incluye al crítico mismo:

10 Insiste en descartar la dicotomía entre nacionalismo y regionalismo frente a cosmopolitismo para considerar sus rasgos productivos, analizando en cada caso las transformaciones que los modelos extranjeros producen en las literaturas latinoamericanas, atendiendo a sus particulares modos de ingreso y a las situaciones culturales especificas en que se insertan: "... Sería ingenuo creer que en todos estos proceso se asiste a un mero traslado, que los valores importados se instalan en un simple vacío, que se aplican tal cual lo hicieran en las metropolis, que trasmutan al hombre latinoamericano todo, como en el misterio de la Eucaristia, sin dejar excipiente alguno de la miga de pan originaria". En La novela en América Latina, 132.

${ }^{20}$ La ciudad..., 9. 
El juicio peca de prevención profesoral sobre los procesos de emergencia de la literatura dentro de la vida concreta - psicológica y social- de un hombre. ... En todos los problemas de la actividad pública de un hombre, las diversas fuerzas antagónicas andan entreveradas, y cuando se trata de la imposición social sobre un artista - icuál no las conoció en su vida?-, más que una lamentación sobre lo que hubiera hecho si no hubiera sido forzado por ella, interesa saber cómo la manejo. El artista no es un ser pasivo: es el otro término de la ecuación que responde a fuerzas que sobre él se ejercen, a las que a veces trata de vencer y, de no lograrlo, intenta utilizarlas en su beneficio. Como no es un ente abstracto, sino un hombre en situación, estos elementos aparecerán siempre en su vida que en definitiva está tejida con ellos. Ni está probado que escribir a las 6rdenes de la actualidad sea obligadamente perjudicial, ... ni que la frecuente superficialidad de Darío responda al periodismo y tampoco que ella sea sinónimo de mala literatura. ${ }^{21}$

En el extenso prólogo a su recopilación de textos de Darío sobre los sueños escritos en un período de profunda crisis del poeta, el de sus últimos años en Europa, Ramarevisa el rol de Darío con sus crónicas al diario La Nación de Buenos Aires - se asume en ellas como intérprete de la burguesía desarrollista y nacional de los países latinoamericanos ligados a los centros europeos frente al avance de los Estados Unidos en sus mercados tradicionales-, y sus conflictos y contradicciones entre su condición de americano y los cambios que operan en sus ilusiones el contacto real con Europa, definiéndolo según los parámetros del colonialismo cultural:

... incapacitado de desprenderse de su propia naturaleza indígena - por no decir latinoamericana-a lo que había de llegarera a una lectura desconsoladora del mundo europeo al que habra tratado de incorporarse. Daria testimonio de Europa desde el ángulo que le era consustancial y que no podía ser el de un indigena pleno, en su mundo propio, ajeno por lo tanto a la acción de los europeos, sino de un indígena marcado por la intervención dominante de ellos. Es decir, un colonizado. ... Todo el drama del colonialismo, en el campo de la cultura, se hace presente en la aventura intelectual cumplida por el poeta. ${ }^{22}$

Otro aspecto importante para encuadrar la figura de Ángel Rama, otro rasgo definidor de su personalidad intelectual, proviene también de esos años en que inicia sus actividades en el campo intelectual uruguayo. Por entonces comienzan sus viajes fuera del país, los que alcanzarán a partir de fines de la década del sesenta una dinámica intensa y atravesada en los setenta por la dura realidad del exilio ${ }^{23}$ que, por una parte moviliza su actividad contra la represión

\footnotetext{
${ }^{21}$ En Rubén Darto y el modernismo (Caracas: Universidad Central de Venezuela, 1970), 71-72.

${ }^{22}$ Rubén Darío. El mundo de los sueños. Edición, prólogo y notas de Ángel Rama (Puerto Rico: Editorial Universitaria, 1973), p. 32. El prólogo lleva la fecha de 1971.

${ }^{23} \mathrm{El}$ golpe de Estado en Uruguay en 1973 lo sorprende fuera del país y ya no volverá a él. Su primer alejamiento del Uruguay ocurre en 1955: permanece durante un año en Paris becado por la embajada francesa.
} 
durante la dictadura uruguaya, y por otra, robustece sus reflexiones acerca de la situación de exilio - reiterada experiencia del escritor latinoamericano-, de los condicionamientos a la libertad intelectual tantoen las sociedades capitalistas como en las socialistas -preocupación evidenciada en Marcha desde 1958 respecto de la Unión Soviética- o lo lleva al análisis de la novela sobre las dictaduras en nuestro continente. ${ }^{24}$ El exilio coopera en intensificar sus vínculos con los diferentes centros americanos favoreciendo a la vez su comprensión de los procesos culturales y literarios y, quizás sobre todo, la dimensión religadora que signa sus proyectos, cuya finalidad úl tima reside en el logro de la integración latinoamericana:

- La integración cultural es un intento revolucionario que, en cuanto tal, se propone un futuro, construyendo la visión utópica de un continente y de una sociedad ideal. ${ }^{25}$

Este propósito, en el que se descubren resonancias de esa "tierra de la promesa" de Pedro Henríquez Ureña, unido a las coincidencias de biografía intelectual y la impronta de un latinoamericanismo abierto a los lazos con lo universal, nos permiten articular afiliaciones de Ángel Rama con otras del pasado, como la de Henríquez Ureña, que él mismo convalida:

Así yo, un día, descubrí en mi camino a Pedro Henríquez Ureña a quien no pude conocer y sentí que él había dicho lo que confusamente había vivido y buscado: que nosotros lo hombres latinoamericanos sólo podemos existir con una viva conciencia utópica, si por ella se entiende la satisfacción de nuestros apetitos humanos y espirituales .... ${ }^{26}$

Estas afiliaciones trazan una red genealógica que pareciera encontrar en la figura de Martf la imagen de padre fundador, expandiéndose hacia el presente en esos nombres que vuelven reiteradamente a sus escritos -Reyes, Silvio Romero, Sanín Cano, y ya entre los contemporáneos, Antonio Cándido-, que respaldan y comparten la significación de su trabajo intelectual. Rama asume

24 "La riesgosa navegación del escritor exiliado" en Nueva Sociedad, 35, marzo de 1978; y para la situación del escritor en Cuba, véase la polémica en torno al caso Padilla y la de Rama con Reinaldo Arenas, entre otros textos, "Reinaldo Arenas al ostracismo" en Eco, 231, enero de 1981; "Política y naturaleza de los exilios latinoamericanos" en Cuadernos de Marcha, 2da. época, n. 8, julio-agosto de 1980; "Norberto Fuentes: el narrador en la tormenta revolucionaria" en Literatura y clase social (Buenos Aires: Folios, 1983). Sobre este punto debe tenerse en cuenta también su renuncia al Comité de Colaboración de Casa de las Américas en 1971, que integraba desde 1964; vuelve a colaborar en la revista en 1982.

${ }^{25}$ "La Biblioteca Ayacucho como instrumento de integración clutural latinoamericana" en Latino-América , 4, 1981, citado en Carina Blixen, 50.

${ }^{26}$ Carina Blixen, 58. 
aquello que considera sus responsabilidades - a despecho del deseo de atender a demandas másíntimas, escribir sobre poesía, por ejemplo-, comorespondiendo a aquel mandato de Alfonso Reyes en Río de Janeiro de $1932,{ }^{27}$ de contribuir, por una parte, a la intercomunicación, al libre flujo del diálogo en nuestro continente (“... es urgente un Servicio de Transmisiones de la Cultura en América Latina"), ${ }^{28}$ y por otra, de establecer un orden en las expresiones literarias de sus distintas áreas construido a partir de parámetros correctos ("... es tarea del crítico intentar un orden dentro de selva tan enmarañada").29 Este voluntarismo, canalizado en un afán fuertemente religador - y la religación fue uno de los ejes posibles de articulación de las literaturas latinoamericanas sobre el cual reflexionó insistentemente- y el modo general en que asume su trabajo parecieran justificar el visualizarlo como un "crítico civil", comprometido con esa herencia de linajes intelectuales que por momentos cobran valores de verdadera filiación. Esto sucede, por ejemplo, con Blanco Fombona, por quien dice sentir:

una de esas admiraciones que parecen corresponder a cierta consanguineidad. Fue uno de esos hombres de pelea que pagaron duramente por decir la verdad: 27 años de exilio por hablar claro sobre Gómez. Suelo asociarme a él cuando pienso que debió pasar buena parte de su vida adulta fuera de la patria, sin poder servirla como quería, y que uno de los trabajos que más lo apasionaron en el destierro español fue fundar una editorial, América, en la que por primera vez se difundió la historia, la literatura, la filosofía y -en general-el pensamiento de América Latina. Diría que Blanco Fombona fue precursor de la Biblioteca Ayacucho, y si ésta no se llamara como se llama, debería llevar su nombre. ${ }^{30}$

\section{RAMA Y LA GENERACIÓN CRÍTICA}

Una última muñeca china, porque no ha sido específicamente enunciada hasta ahora en este trabajo, pero que funciona comola inicial, es la integración

\footnotetext{
27 “Relacionad, pues, a nuestros hombres de pensamiento unos con otros. Sed ingeniosos e incansables; discurrid medios para crear los vasos comunicantes; labor de prensa, correspondencia, obligación de cambiar libros a través de organismos adecuados ..., sistemas de investigación paralela! ¡Qué se yo!". En Ultima Tule, Obras completas (México: Fondo de Cultura Económica, 1959), vol. XI, 70.

${ }_{28}$ "La generación hispanoamericana del medio siglo. Una generación creadora" en Marcha 1217 (Montevideo: 7 de agosto de 1964) incluido en Aurora M. Ocampo, comp., La critica de la novela iberoamericana contemporánea. Antologia (México: Universidad Nacional Autónoma de México, 1973), 19 y 21 respectivamente.

${ }^{29}$ Adriana Astutti, Sandra Contreras y Marcela Zanín, "Angel Rama: edificación de una literatura popular para América Latina" en Varios autores, Homenaje a Angel Rama (Santa Fe, Argentina, Cuadernos de la Comuna 25, 1990), 25.

${ }^{30}$ Blixen, 52.
} 
de ngel Rama en el equipo de Marcha como encargado de la sección literaria a partir del número 950 , de 1959 , y en la que continuará hasta $1968 .^{31}$

Cuando Ramaingresa al grupo de los "hepáticos" de Marcha, representante de la izquierda independiente que constituye una de las empresas políticas y culturales más significativas de América Latina por la seriedad de su información y por los alcances de su difusión, el periódico cumple veinte años, y siempre bajo la dirección de Carlos Quijano. ${ }^{32}$

La etapa en que actúa Rama estará marcada por hechos de enorme importancia para América Latina, tanto en el terreno político e ideológico - la Revolución Cubana, con los riesgos de invasión y el bloqueo, la invasión de los Estados Unidos a la República Dominicana, la acción de los movimientos guerrilleros, la guerra de Viet-Nam, entre otros-, como en el cultural -la concreción del boom, la presencia cada vez más visible del mercado literario y la industria cultural, de los medios de comunicación masiva (con la presencia inédita de la televisión), el inicio del caso Padilla, etc. Todos ellos influyen en introducir o en fortalecer en el debate de ideas, que define a Marcha, los conceptos de tercermundismo, nacionalismo y latinoamericanismo, antiimperialismo, así como la discusión acerca de:

los pactos que vinculan a los intelectuales con la sociedad y fundamentalmente, que legitiman ideológicamente su trabajo y su existencia como tales. ${ }^{33}$

Como integrante de "Lageneración crítica", cuando se entrega a la tarea de articularla y definirla, luego del fracaso del Frente Amplio, coloca a la revolución del campo cultural en lugar privilegiado para responder a las preguntas angustiadas del uruguayo común:

¿Qué nos ha pasado? ... ¿Cómo fue que se nos perdió aquel Uruguay? ¿Cómo se concluyó así, tan de golpe, el bienestar, el civilismo, la democracia? ${ }^{34}$

\footnotetext{
${ }^{31}$ Comienza a ejercer la crítica literaria periodística en 1945 en El Pats de Montevideo y la continúa luego en El Nacional (1954) y en Acción (1957-1964). También lo hace en medios más especificos: Clinamen (1947-1948), Entregas de la Licorne (1953-1956), o en la Revista Iberoamericana de Literatura de la Universidad de Montevideo (1966-1970) y Escritura de Caracas, entre cuyos fundadores se cuenta en 1976.

${ }^{32}$ Marcha sufrío su primera clausura el 20 de octubre de 1967, cuando todavia Rama integraba su equipo. Fue definitivamente clausurada en 1974. Cuando aparecen en México los Cuadernos de Marcha, Rama reinicia su colaboración (1981).

${ }^{33}$ Me han sido de gran utilidad las investigaciones de Claudia Gilman sobre Marcha, Una empresa polttico cultural: El semanario Marcha en la década del sesenta y Perspectivas sobre polttica y cultura. El semanario uruguayo Marcha a partir de los sesenta (Buenos Aires: mimeo, 1989). La cita proviene de este último, 43.

${ }^{34}$ La generación critica (1939-1969) (Montevideo: Arca, 1972). La cita proviene de Ángel Rama, La critica de la cultura en América Latina. Selección, prólogos Saúl Sosnowski y Tomás Eloy Martínez (Caracas: Biblioteca Ayacucho, 1985), 217.
} 
En ese tiempo propio, tiempo del "sacudimiento" para Rama, la generación crítica asiste al derrumbe del régimen liberal uruguayo, del cual se convirtió en sus "sepultureros ideológicos". ${ }^{35}$

La crítica de Rama al liberalismo uruguayo se detiene en el análisis de las causas del deterioro cultural: "la reacción de las derechas ante el triunfo cubano de 1959", la acción de los intereses norteamericanos visualizada en la penetración cultural, el empobrecimiento de amplios sectores de la población y la ausencia de una política estatal coherente, que funcione como "instrumento de acción y de progreso".

Contra tal putrefacción -afirma- sólo cabe asumir los principios de una cultura militante, en la gran tradición de la cultura universal y nacional", atendiendo a los problemas actuales de amplios sectores, sin "rémoras folkloricas" para "mantener la función creadora y adoctrinadora del arte. ${ }^{36}$

El carácter crítico y programático de este texto es buen ejemplo de los cambios que se producen en la sección literaria de Marcha con el ingreso de Rama: la articulación más orgánica del análisis de los diferentes fenómenos que inciden en el estancamiento y la atonía cultural uruguaya y el desarrollo de propuestas para revertirlos -en el campo de los organismos oficiales, de la educación, del mercado editorial, de los medios de comunicación masiva-, sin descuidar la reflexión de los modos en que el arte y el intelectual pueden operar en tales transformaciones. En su artículo "Del provincianismo cultural" recusa la "escasa audacia inventiva y descubridora dentro de la del campo de la modernidad artística", de las expresiones artísticas uruguayas comparadas con otras experiencias de renovación en América Latina - cita a Vargas Llosa, Cortázar, García Márquez, Cardenal, etc.-, señalandoa la vez la responsabilidad que les cabe a las élites y a los creadores mismos, y a la entera sociedad nacional.

La atonía del país, su falta de una concepción dinámica generosa que lo ponga en funcionamiento para un fin superior, para un fin común, o simplemente para intentar un esfuerzo, se traduce también en el campo de la cultura - donde la resistencia es mayor, dondela lucha es más tenaz-impregnando de escepticismo, de "cansera" como dice el paisano, los productos artísticos; de irrealidad muchas de la concepciones intelectuales. ${ }^{37}$

La brega por la recomposición o la transformación del campo intelectual uruguayo, primordial por su peso en el cambio de la sociedad uruguaya misma, dirige la sección literaria de Marcha, atenta a la modernización —el esfuerzo

\footnotetext{
${ }^{35}$ La generación critica (1939-1969), 223.

36 "Por una cultura militante" en Marcha, 1287, 31 de diciembre de 1965. La primera página de esta segunda sección de Marcha, con un gran titular del artículo de Rama, insiste en el grabado en el peso de la televisión como formadora del gusto popular.

${ }_{37}$ "Del provincianismo cultural" en Marcha 1245, 26 de febrero de 1965, 29.
} 
por la nacionalización entraña el colocar al Uruguay "en el concierto mundial" combatiendo un regionalismo cerrado y conservador; implica la formación de un público informado y competente, y el aliento de los jóvenes creadores a través de concursos, de políticas editoriales adecuadas. De allí la presencia de notas sobre "¿Qué leen los uruguayos?", las ferias del libro, las relaciones entre escritores y público o sobre nuevas editoriales latinoamericanas. ${ }^{38}$ Se trata, en suma, de poner en marcha ese proyecto formulado al año de su ingreso: "La construcción de una literatura" nacional, a partir de la conciencia de sus lazos con la sociedad de la que ella proviene:

No basta que haya obras literarias buenas y exitosas para que exista una literatura. Por eso, las obras y los movimientos estéticos deben responder a una estructura armónica, con continuidad creadora, con vida real que responda a una necesidad de la sociedad en la cual funcionan. ${ }^{39}$

Los presupuestos de Antonio Cándido - presentes en esa articulación orgánica de la literatura uruguaya como institución-presidirán luego la tarea similar que emprende con la literatura latinoamericana, cuyas dificultades expone en Marcha en 1964_-'No hay literatura de más difícil conocimientoy sistematización que la llamada literatura hispanoamericana". ${ }^{40}$ Esa es literatura que palpa sobre todo en la nueva narrativa que surge en los sesenta, venciendo situaciones no demasiadolejanas de las que peculiarizan negativamente al medio uruguayo, la que sirve de marco sustentador de la débil literatura nacional. ${ }^{41}$ Su difusión

${ }^{38}$ Véanse: "Una encuesta de Angel Rama: ¿Qué leen los uruguayos?", Marcha 1038, 9 de diciembre de 1960; "En este país: la Feria por dentro, o el arte de vender uruguayos", n. 1044, 27 de enero de 1961; "Un país sin libros", n. 1061, 9 de junio de 1961; "En este país: los escritores y el público", n. 1077, 29 de setiembre de 1961; "Editora para el hombre actual: Era”, n. 1110, 8 de junio de 1962; “'Para qué sirven las revistas?", n. 1161, 21 de junio de 1963; "Movilización de artistas e intelectuales: hacia una central de la cultura", n. 1176, 4 de octubre de 1963, etc.

${ }^{39}$ Se trata de una encuesta a escritores uruguayos desarrollada entre los números 1003 y 1015 de Marcha. La cita proviene de Claudia Gilman, 40. Las relaciones entre vida social y narrativa así planteadas, adelgazando su complejidad y las mediatizaciones inherentes, inician también los "Diez problemas para el novelista latinoamericano", publicado originalmente en Casa de las Américas, n. 26 de oct.-nov. de 1964: "Si este tiempo se nos presenta urgido, desgarrado, contradictorio, como en época de revolución inminente, así también se nos presentará el panorama de la creación artística" (Caracas: Sintesis Dosmil, 1972), 8.

40 "La generacion del medio siglo" en Aurora Ocampo,op. cit., 17. Originalmente en Marcha, 1217,7 de agosto de 1964.

41 “... si en líneas generales ya es posible hablar de una cultura latinoamericana (o hispanoamericana) con direcciones y valores propios, tónicas y medios característicos, parece bastante más difícil registrar la autonomía o la mera existencia de las literaturas nacionales" en Diez problemas ..., 28-29. 
y análisis recaen en la responsabilidad del crítico, constituyendo su función social. Rama responde a tal imperativo con la constante inserción de notas y artículos críticos, inclusión de textos o introducción de colaboradores latinoamericanos -Richardo Latcham, César Fernández Moreno, etc.- y con el examen abarcador de las condiciones, problemas y modalidades de producción de la narrativa latinoamericana.

Podríamos afirmar que los temas y los problemas literarios expuestos en los años de Marcha, con un tratamiento más matizado de sus complejidades, persisten hasta sus últimas contribuciones: la perspectiva culturalista, las convicciones acerca de la función social del arte, el hacer de los vínculos entre literatura, sociedad y cultura un punto focal prioritario para responder acerca de la originalidad de la literatura latinoamericana, así como la atención a los problemas entre ideología y poética ${ }^{42} \mathrm{o}$ el reiterado interés por el realismo-sea a través de sus reformulaciones en la producción narrativa o en la teoría literaria-, todo ello acompañado de la flexión hacia las consideraciones sobre el quehacer crítico. Marcado evidentemente por los conflictos y las expectativas de los sesenta como por la reversión de estas últimas y la consiguiente necesidad del replanteo, sin embargo, la persistencia de los modos de operar de Rama tanto en la actividad intelectual inmediata como en la investigación- han dejado la posibilidad de poder establecer con sus textos, tan datados, esa doble lectura que señaló de su revisión de la obra de Henríquez Ureña.

Esa doble lectura favorecía un entendimiento mejor de la cultura latinoamericana, porque recuperaba la producción literaria y al tiempo las estructuras de significación que se diseñaron en un perído..$^{43}$

\section{LA UNIDAD POSIBLE}

En una de sus últimas colecciones de ensayos, Literatura y clase social, al explicitar el eje que les da unidad confirma nuestras apreciaciones recién apuntadas. Crisis y crítica reconocen un origen común; una convoca a la otra y la sitúa no sólo en un campo cultural, sino que la obliga en estas sociedades latinoamericanas a una definición, a una toma de posición, que incluye todo lo que aquí entraña la condición humana. Los períodos de crisis, el momento crítico, apelan el “decido, separo, juzgo" -manifiesto en su etimología:

el cual mal podría verse como una función incontaminada, abstracta y pura, sino como la obligada tarea de un hombre latinoamericano para quien este continente,

\footnotetext{
42 Recuérdense, a modo de ejemplo, sus trabajos, "Indagación de la ideologra en la poesía (los dípticos seriados de Versos sencillos)" en Revista Iberoamericana, 112-113, juliodiciembre de 1980; “ "Los ríos profundos, 6pera de pobres" en Revista Iberoamericana, 122 , enero-marzo de 1983.

${ }^{43}$ En La novela en América Latina , 15.
} 
esta cultura, esta aspiración al reino de la justicia, son prioritarios. No será posible sin una comprensión, la más objetiva posible, del funcionamiento de la sociedad que genera esa cultura, esas letras, esas esperanzas.44

La crisis que arrasó con las expectativas de la década del sesenta, presente en su alejamiento de Marcha, y del cierre de Marcha misma, dieron otra vuelta de tuerca a la presuposición etimológica de su común sentido: la mirada crítica corre el riesgo de desgarrarse ante la frustración y el fracaso que la crisis entraña, o elegir el encierro que cercena la función social que se le atribuye. Rama se mantiene fiel alaidea de construcción-podríamos también encuadrarla en reconstrucción - de una literatura, al gesto globalizante, que incluye el "reexamen" de su funcionamiento en el sistema social latinoamericano. Tal construcción tiende al rechazo del concepto acuñado por Octavio Paz, de una historia literaria estructurada sobre la base de rupturas. Rama busca continuidades que perfilen tradiciones, modos de operar con la lengua, con los conflictos, con los lenguajes simbólicos o con el imaginario social que van tejiendo esas redes en que se reconocen respuestas propias latinoamericanas, siempre en tensión y en diálogo con las experiencias - textuales, ideológicas, estéticas y sociales- ajenas. Por esos hilos asciende la posibilidad de la expresión plena americana, su trama va relegando en el pasado el aislamiento de unas pocas obras literarias, va abriendo al crítico atento los ejemplos que permiten vislumbrar o palpar lazos, sea entre las distintas áreas latinoamericanas, sea entre la literatura y los diferentes estratos sociales, sea entre las diversas, y a veces encontradas, propuestas estéticas - su idea de las dos vanguardias, por ejemplo. Respuestas mestizas, que imbrican experiencias plurales: mestizaciones literarias, "Nootra cosa han sido sus mayores creaciones artísticas".45 Las mupturas, que presiden el reexamen, expresan las crisis sociales, y es en este sentido que pueden constituirse en eje de análisis, pero un eje que vuelve a suturar, pues permite religar esa relación imprescindible entre el arte y los contextos culturales y sociales en que emerge.

Las literaturas latinoamericanas pueden articularse en función de los paralelismos que sus campos culturales evidencian, por la incidencia de los modelos extracontinentales y por los lazos que guardan con las sociedades que les son propias. Con estos datos, el crítico, reacio a sepultar la utopía, religa, traza redes de encuentro - palpa también las concretas-, escribe, la unidad posible.

${ }^{44}$ Literatura y clase social (Buenos Aires: Folios, 1983), 13.

${ }^{45}$ Literatura ..., 22. 